\title{
DM-GRASP Is Necessary for Nonradial Cell Migration during Chick Diencephalic Development
}

\author{
Daniel S. Heffron and Jeffrey A. Golden \\ Department of Pathology, Children's Hospital of Philadelphia and the University of Pennsylvania School of Medicine, \\ Philade/phia, Pennsylvania
}

Cell migration is fundamental to normal CNS development. Radial migration, along radial glial fibers, has been the principal pathway studied, however, nonradial or tangential cell migration has increasingly been identified at all levels of the CNS. Receptors, cell adhesion molecules, and extracellular matrix molecules have all been shown to participate in radial cell migration. In contrast, the molecular basis of nonradial cell migration has only recently begun to be elucidated. Using replication defective retroviral vectors we have determined the location and time when nonradial cell migration begins in the developing chick diencephalon. We have identified three molecules that are expressed in spatially and temporally restricted domains that are consistent with them playing a role in nonradial cell migration. One of these molecules, DM-GRASP, a transmembrane protein with five extracellular Ig domains, is expressed on the nonradially migrating cells in addition to

One of the remarkable features of CNS development is the extensive cell migration that occurs from the site where progenitor cells reside to where a postmitotic, terminally differentiated cell resides in the mature brain. Neurons and glia are derived predominately from progenitor cells located adjacent to the lumen of the neural tube. These regions, known as the ventricular zone (VZ) and subventricular zone (SVZ), are composed of proliferating cells. The two daughter cells resulting from a cell division may each re-enter the cell cycle, one may re-enter the cell cycle and the other may leave the cell cycle, or both may exit the cell cycle. Those cells that exit the cell cycle begin differentiation. As cells differentiate, they also migrate away from their site of birth to where they will reside in the mature nervous system.

Two major pathways of cell migration have been identified during early development; radial, from the ventricular zone out toward the surface of the neural tube, and nonradial or tangential, which is parallel to the surface of the neural tube. Radial migration was the first pathway of migration to be identified and subsequently is the best characterized. Radial cell migration is also known as glial-guided cell migration because the neuroblasts

\footnotetext{
Received Aug. 18, 1999; revised Dec. 8, 1999; accepted Jan. 5, 2000.

This work was supported by the Klingenstein foundation and the National Institutes of Health. We would like to thank Dr. S. Chang for providing us with the DM-1 and DM-2 antibodies. Dr. J. Sanes kindly provided the LZ-12 producing cell line. The 5E1 and 8D9 antibodies were provided by the Developmental Studies Hybridoma Bank, University of Iowa. We thank the members of the Golden laboratory and Dr. D. Pleasure for their constructive criticism.

Correspondence should be addressed to Jeffrey Golden, Department of Pathology, Abramson Research Center, Room 516c, Children's Hospital of Philadelphia, 3400 Civic Center Boulevard, Philadelphia, PA 19104. E-mail: goldenj@mail. med.upenn.edu.

Copyright (C) 2000 Society for Neuroscience $\quad 0270-6474 / 00 / 202287-08 \$ 15.00 / 0$
}

axons. To test the hypothesis that DM-GRASP participates in guiding nonradial cell migration, we injected a replicationdefective retroviral vector used for lineage tracing followed by a DM-GRASP blocking antibody. Embryos injected with the blocking antibody showed a near complete block in nonradial cell migration specifically where DM-GRASP is expressed. Furthermore, morphological analyses revealed disruption of the normal architecture of the diencephalon indicating nonradial cell migration is necessary for normal morphological development of the brain. Our data indicate that DM-GRASP is necessary for nonradial cell migration in the chick diencephalon and have provided a system to further explore the function of nonradial cell migration during CNS development.

Key words: nonradial cell migration; tangential cell migration; DM-GRASP/BEN; diencephalon; chick; CNS migrate along specialized glial cells known as a radial glia (Rakic, 1990; for review, see Hatten, 1999). In vitro and in vivo studies of radial cell migration have identified a number of molecules that participate in this pathway of migration. These molecules fall into several broad categories, including extracellular matrix molecules (Husmann et al., 1992; Fishman and Hatten, 1993), cell surface molecules (including receptors, ligands, and cell adhesion molecules) (Stitt and Hatten, 1990; Fishell and Hatten, 1991; Asou et al., 1992; Grumet, 1992; Fishman and Hatten, 1993; Komuro and Rakic, 1993, 1996; Mittal and David, 1994; Ono et al., 1994; Thomaidou et al., 1995; Anton et al., 1996; Zheng et al., 1996; Anton et al., 1997; Rio et al., 1997), secreted molecules, and molecules with putative roles in signal transduction (Anton et al., 1997; Rio et al., 1997).

In contrast to radial cell migration, relatively little is known about the guidance of nonradial (also defined as tangential) cell migration. Nonradial cell migration has been observed at virtually every level of the developing nervous system including the spinal cord (Leber et al., 1990; Phelps et al., 1996), hindbrain (Baehr et al., 1988; Bourrat and Sotelo, 1988; Leber et al., 1990; Marin and Puelles, 1995; Ono and Kawamura, 1989; Phelps et al., 1996), cerebellum (Ryder and Cepko, 1994), midbrain (Gray and Sanes, 1991; Martinez et al., 1992), diencephalon (Golden and Cepko, 1996; Golden et al., 1997), and telencephalon (Austin and Cepko, 1990; Halliday and Cepko, 1992; Walsh and Cepko, 1992; Fishell et al., 1993; O’Rourke et al., 1995, 1996, 1997; Szele and Cepko, 1996, 1998; Anderson et al., 1997; Tan et al., 1998). Furthermore, clonal analysis and cell labeling studies indicate that a significant percentage of cells move along tangential pathways during development. For example, up to $40 \%$ of clones in the chick dienceph- 
alon showed nonradial dispersion (Golden et al., 1997), and up to $30 \%$ of cells in the cerebral hemispheres of ferret also showed nonradial dispersion (O'Rourke et al., 1995).

The molecular and cellular mechanisms that direct cells to leave their radial pathway and move along nonradial pathways are beginning to be characterized. Using a library of replicationdefective retroviruses we have previously determined the time during development and the location within the wall of the neural tube where nonradial migration begins in the chick diencephalon (Golden et al., 1997). Our data indicate that nonradial cell migration begins between embryonic day 4 (E4) and E5 and that the migration occurs outside the ventricular zone. Based on these data, we hypothesized that the molecules guiding nonradial cell migration must be expressed in this spatial and temporal pattern.

DM-GRASP was identified as a candidate molecule because it was found to have the expression pattern predicted for a molecule that would participate in nonradial cell migration. DM-GRASP is a type I transmembrane protein with five Ig-like domains and many putative $N$-glycosylation sites on the $\mathrm{N}$-terminal end (Burns et al., 1991). Antibodies to DM-GRASP have been independently generated by three groups (Tanaka and Obata, 1984; Pourquie et al., 1990; Burns et al., 1991). Using three distinct antibodies to DM-GRASP, we found that this protein is expressed on the surface of cells as well as on axons of other cells within the region of nonradial cell migration. To test if DM-GRASP is necessary for nonradial cell migration, functional blocking antibodies [based on an in vitro axon outgrowth assay (Burns et al., 1991) were injected after the injection of a lineage tracer (Golden et al., 1995)]. Nonradial cell migration was specifically blocked in the chick diencephalon after injection of a blocking antibody. These data suggest that DM-GRASP is necessary for nonradial cell migration. Nonradial cell migration may also be crucial for normal CNS development because injection of DM-GRASP blocking antibody results in abnormal morphological development of the diencephalon. These data indicate DM-GRASP is necessary for nonradial cell migration. We expect DM-GRASP is only one of what will likely be many molecules required for nonradial cell migration, similar to radial cell migration.

\section{MATERIALS AND METHODS}

Retroviral labeling. A replication-defective avian retrovirus, CHAP (a gift from Dr. C. Cepko), which encodes human placental alkaline phosphatase in place of the viral gag and pol genes, was produced according to published protocols (Ryder and Cepko, 1994). A second replicationdefective avian retrovirus, LZ12 (a gift from Dr. J. Sanes), which encodes the Escherichia coli LacZ gene after a nuclear localizing sequence, was produced according to published protocols (Galileo et al., 1990). Both viral stocks were tested and found not to contain helper virus, and stocks were used with titers of between $10^{6}$ and $10^{7} \mathrm{cfu} / \mathrm{ml}$. Chick neural tube infection was achieved by injecting $0.3-1.5 \mu$ l of concentrated retrovirus into fertilized, virus-free White Leghorn embryos at stage 10-14 (Hamburger and Hamilton, 1951), as previously described (Golden et al., 1995; Golden and Cepko, 1996). Embryos were harvested on E6, E10, or E14 (brain only on E10 and E14) and fixed overnight at $4^{\circ}$ in $4 \%$ paraformaldehyde in $0.1 \mathrm{~m}$ PBS, $\mathrm{pH}$ 7.4. For alkaline phosphatase staining, embryos were heat-inactivated at $65^{\circ} \mathrm{C}$ for $1 \mathrm{hr}$ to destroy endogenous alkaline phosphatase (AP) activity and developed in nitroblue tetrazolium (Sigma, St. Louis, MO) and 5-bromo-4-chloro-3-indolyl-phosphate (Sigma) as previously described (Golden et al., 1995). Embryos showing infection within the diencephalon were equilibrated overnight in $30 \%$ sucrose in PBS, embedded in OCT, and sectioned coronally on a Reichert-Jung cryostat at $30 \mu \mathrm{m}$. Sections were collected consecutively on Superfrost/Plus slides (Fisher Scientific, Pittsburgh, PA) and baked overnight at $37^{\circ} \mathrm{C}$. Sections were then redeveloped for AP activity, and the distribution of cells were examined on a Nikon E400 compound microscope.

Embryos injected with LZ12 were fixed and processed as described above except that they were cut at $20 \mu \mathrm{m}$ and they were not incubated at $65^{\circ} \mathrm{C}$. After washing in PBS, the embryos were placed directly into 1 $\mathrm{mg} / \mathrm{ml}$ 5-bromo-4-chloro-3-indolyl-galactoside (Sigma) made in detection buffer ( $35 \mathrm{~mm}$ ferricyanide, $35 \mathrm{~mm}$ ferrocyanide, and $5 \mathrm{~mm} \mathrm{MgCl}_{2}$ in PBS). Embryos were incubated overnight and then washed three times in PBS. Embryos with infection in the diencephalon were further processed and cryosectioned for light microscopic examination as described above and immunohistochemistry as described below.

Antibody injections. DM-1 and DM-2 hybridomas were a gift from Dr. Susannah Chang. Blocking (DM-2) or control (DM-1) hybridoma supernatant was centrifuged and filtered through a $0.2 \mu \mathrm{m}$ membrane. Fast green dye was added to the supernatant at a final concentration of $0.0125 \%$. The antibody was injected into a vitelline vein on the surface of the yolk at a rate of $3-5 \mu \mathrm{l} / \mathrm{min}$ through a heat-pulled micropipette attached to a $100 \mu \mathrm{l}$ Hamilton syringe. Approximately $12 \mu \mathrm{l}$ was injected on E4 and $16 \mu \mathrm{l}$ on E5, followed by harvesting on E6. DM-1 and DM-2 were also concentrated with a protein-A column and dialyzed against PBS to an estimated concentration of $500 \mu \mathrm{g} / \mathrm{ml}$. Four microliters of the concentrated antibody were injected on E4 and $6 \mu \mathrm{l}$ on E5. The injection of smaller volumes of concentrated antibody appeared to improve embryo survival. For those embryos harvested on E10 and E14, in addition to the injection of antibody on E4 and E5, $20 \mu \mathrm{l}$ was injected on E6.

Immunohistochemistry. Cryosections prepared as described above for viral histochemistry were rinsed in PBS, and sections were blocked in $10 \%$ goat serum, $0.1 \%$ Tween-20 in PBS, and incubated in primary antibody for $1 \mathrm{hr}$ at room temperature to overnight at $4^{\circ} \mathrm{C}$. Primary antibodies included Tuj1 (neuron-specific class III tubulin; Geisert and Frankfurter, 1989), 1:100; 8D9 (Ng-CAM; Lemmon and McLoon, 1986), 1:10; 5E1 (sonic hedgehog; Ericson et al., 1996) undiluted; DM-1 and DM-2 (both recognize DM-GR ASP; Burns et al., 1991), undiluted. After washing in PBS, sections were incubated for $1 \mathrm{hr}$ with the appropriate secondary antibody conjugated to Texas Red or fluorescein isothioscyanate (Jackson ImmunoResearch, West Grove, PA). Sections were washed in PBS, coverslipped with Vectashield (Vector Laboratories, Burlingame, CA), and examined with a Zeiss Axioplan microscope equipped with epifluorescence.

Antibodies injected in vivo were detected by fixing and processing the embryos as described above. Sections were rinsed in PBS and blocked as described above. After blocking, the embryos were incubated directly in the appropriate secondary followed by washing in PBS and then coverslipped with Vectashield. Sections were again examined with a Zeiss Axioplan microscope equipped with epifluorescence.

Histology. Antibody injected or control E10 and E14 brains were quickly dissected out in PBS and fixed overnight in $4 \%$ paraformaldehyde in PBS at $4^{\circ} \mathrm{C}$. Brains were then rinsed in PBS, dehydrated, and infiltrated with paraffin without vacuum. The brains were then oriented in paraffin blocks and cut coronally at $7 \mu \mathrm{m}$ on a Zeiss microtome. Sections were collected and baked on Superfrost/Plus slides (Fisher Scientific) at $37^{\circ} \mathrm{C}$ overnight. Sections were then deparaffinized, rehydrated, stained with hematoxylin and eosin according to standard protocols, coverslipped with Permount (Fisher Scientific), and examined with a Nikon E400 microscope.

BrdU incorporation studies and TUNEL assays. Embryos injected with DM-1 or DM-2 antibody as described above were injected with BrdU solution on E7, E8, or E10. A 30 gauge needle was used to inject $100 \mu \mathrm{l}$ of a $10 \mu \mathrm{g} / \mathrm{ml}$ solution of BrdU in sterile PBS into the amniotic sack. Embryos were harvested into $4 \%$ paraformaldehyde $30 \mathrm{~min}$ after injection. Cryosections were prepared as above. BrdU was detected by incubating cryosections in $2 \mathrm{~N} \mathrm{HCl}$ for $1 \mathrm{hr}$ at $37^{\circ} \mathrm{C}$. Slides were rinsed five times in PBS and incubated for $1 \mathrm{hr}$ in primary antibody (G3G4; Developmental Studies Hybridoma Bank) diluted 1:50 in 1\% bovine serum albumin, $1 \%$ DMSO, $0.1 \%$ Triton X-100, and $10 \%$ goat serum in PBS. Primary antibody was detected as described above. Cell death was assayed by injecting embryos with DM1 or DM2 antibody then harvesting on E7, E8, and E10 as described above. TUNEL assays were performed on cryosections of these embryos as previously reported (Golden et al., 1999). Three embryos were studied at each time point. Sections labeled for BrdU and with TUNEL were counterstained with DAPI and examined on a Zeiss Axioplan microscope with epifluorescence.

\section{RESULTS}

Candidate molecules for guidance of nonradial cell migration in the developing CNS were defined as those expressed in a pattern coincident with the onset of nonradial cell migration (Golden et 


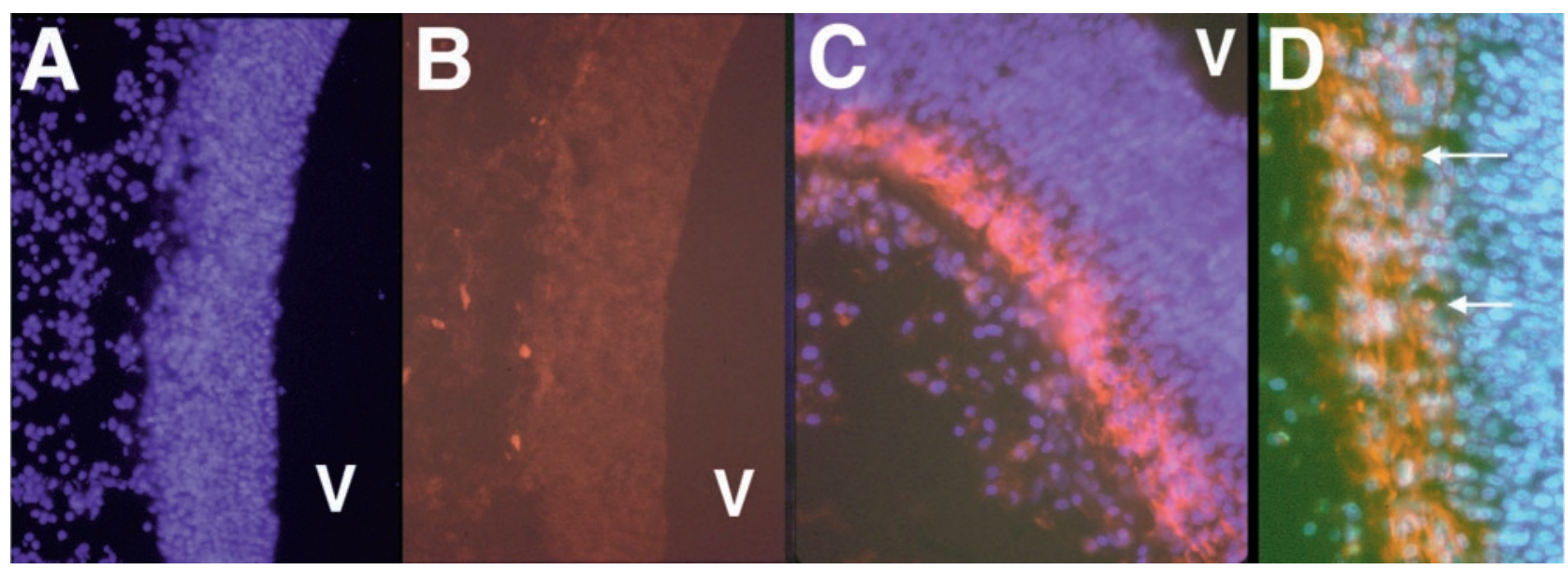

Figure 1. Immunofluorescence with an antibody to DM-GRASP/BEN. On E4, no staining is seen in the wall of the diencephalon $(A$, DAPI staining to show location of diencephalic wall; $B$, secondary antibody conjugated to Texas Red), although occasionally small axons were seen coursing dorsal to ventral. By E5 DM-GRASP/BEN is expressed at high levels outside the VZ $(C$, red fluorescence). At higher magnification $(D)$ individual cells are decorated with the DM-1 antibody (arrows). $V$, Ventricle.

al., 1997). Immunohistochemistry, using existing antibodies to cell adhesion molecules, extracellular matrix molecules, and cell surface receptors, ligands or potential cell-cell interacting molecules was performed on coronal sections of E4 and E5 chick diencephalon. To date, three molecules have been identified as meeting the criteria defined for a candidate molecule. The first of these molecules, Ng-CAM, was previously reported (Golden et al., 1997). The other two are DM-GRASP (Fig. 1) and $\beta_{2}$-laminin (data not shown). Although DM-GRASP is located on subsets of axons before and on E4 (Chédotal et al., 1995), it is also localized on cell bodies at E5 outside the ventricular zone (Fig. 1). This pattern of expression is consistent with DM-GR ASP participating in nonradial cell migration. We also observed DM-GRASP expression outside the diencephalon consistent with previous descriptions (Tanaka and Obata, 1984; Burns et al., 1991; Pourquie et al., 1992; Zhang et al., 1995; Fournier-Thibault et al., 1999).

A functional blocking antibody (DM-2) and a nonblocking antibody (DM-1) to DM-GRASP were previously characterized (Burns et al., 1991). We predicted that if DM-GRASP was necessary for nonradial cell migration, then administration of DM-2 should block nonradial cell migration. To test our hypothesis we first determined that we could localize DM-2 to the sites of DM-GRASP expression in ovo. Hybridoma supernatants from either DM-1 or DM-2 were injected intravascularly and specifically localize to the sites of DM-GRASP expression for up to 24 hr (Fig. 2). The injected antibody could not be detected $36 \mathrm{hr}$ or later. Injection of either DM-1 or DM-2 into the neural tube or the amniotic fluid was not sufficient to localize these antibodies to the sites of DM-GRASP expression in ovo (data not shown). We have tested several other hybridoma supernatants (5E1, anti-Shh and 8D9, anti-NgCAM) and found the intravascular technique to be equally effective, resulting in specific localization of these antibodies in ovo (data not shown).

DM-2 blocks axons from growing out along other axons (Burns et al., 1991). Accordingly, the administration of DM-2 may block axon growth through the diencephalon that could secondarily effect other processes such as cell migration. To investigate this possibility, DM-2 was injected into extraembryonic chick blood vessels on E4.5 and E5.5. The embryonic brain was harvested on E7.5, sectioned coronally, and examined for the presence or

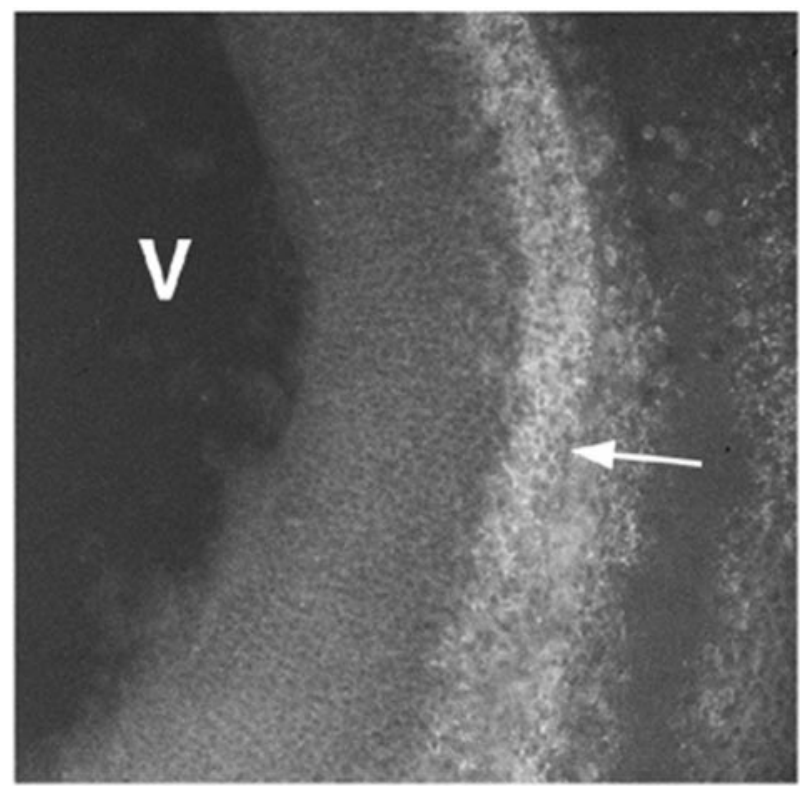

Figure 2. An embryo intravascularly injected at E6 with DM-2 and harvested $12 \mathrm{hr}$ later shows localization of DM-GRASP/BEN on cells (arrow) outside the VZ (compare with Fig. 1c). Sections were treated with secondary antibody conjugated to FITC after fixation and cryosectioning. $V$, Ventricle.

absence of axons previously described in this region (Golden et al., 1997). To avoid false-positive results from the injection of DM-1 or DM-2, embryos were examined with axon markers at least $48 \mathrm{hr}$ after injecting antibody. Axons in these brains are decorated with both the Tuj1 antibody, which recognizes a neuron-specific class III $\beta$-tubulin (Fig. 3), and the 8A1 antibody, which recognizes low molecular weight neurofilament protein (data not shown), both of which label early axons traversing the diencephalon (Golden et al., 1997). Thus, DM-2 did not block axons from growing through the diencephalon. These data do not preclude a quantitative difference in the number of axons or the fasciculation of axons traversing through the diencephalon, however, no qualitative difference between control and injected embryos was identified. 


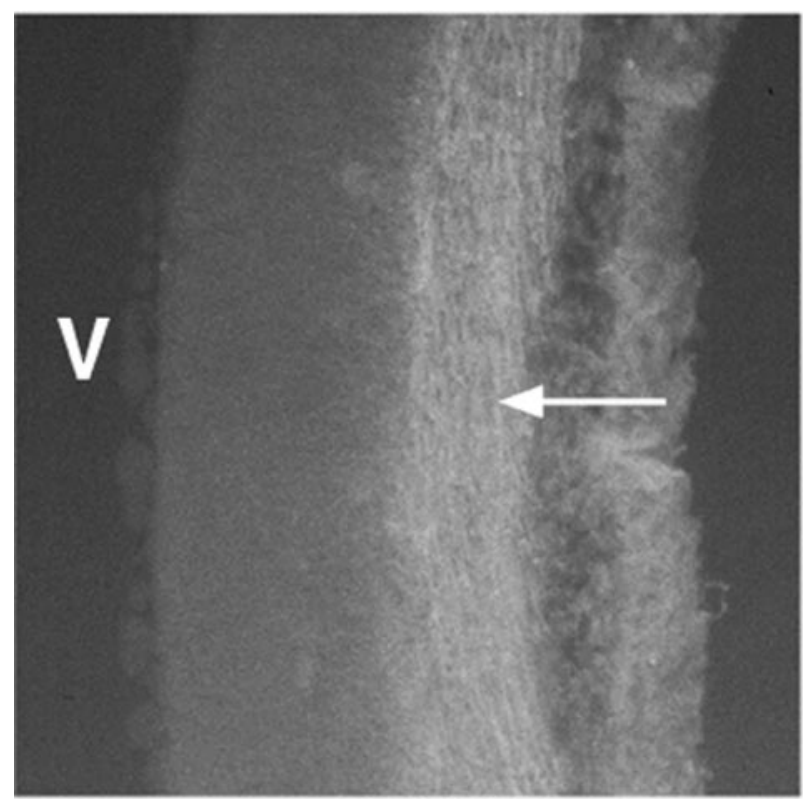

Figure 3. Axons were immunolabeled with Tuj1, indicating that DM-2 treatment did not disrupt early axon growth through the diencephalon (arrow points to labeled axons). Embryos were treated on E4 and E5 with DM-2 and evaluated on E7. $V$, Ventricle.

We next investigated whether DM-2 blocked nonradial cell migration. Stage 10-13 embryos were injected with a replicationdefective retroviral vector (Golden et al., 1995) followed by intravascular injection of DM-2, DM-1, or PBS on E4 and E5. On E6 embryos were fixed, washed, and alkaline phosphatase (CHAPOL-injected embryos; Golden et al., 1995) or $\beta$-galactosidase (for LZ12-injected embryos; Galileo et al., 1990) histochemistry was performed to determine which embryos had CNS infection. Embryos with clones in the CNS were processed for cryosectioning and sectioned in the coronal plane.

The injection of DM-2 specifically blocked nonradial cell migration in the diencephalon (Fig. 4, Table 1). Nonradial dispersion of cells was seen in approximately one-third of all clones after PBS injections (Table 1). Embryos injected with DM-1 showed nearly a third of clones with both radial and nonradial cell dispersion, similar to the distribution of clones in control embryos (Table 1). In contrast, embryos injected with DM-2 showed only two clones with nonradially dispersed cells. Furthermore, the two clones with nonradial cell migration were found in the most ventral aspect of the diencephalon where DM-GRASP is not expressed. The three groups (no antibody, DM-1, and DM-2) were compared by $\chi^{2}$ analysis, and the difference between these groups was found to be statistically significant $\left(\chi^{2}=7.73 ; p<\right.$ 0.025) (Sokal and Rohlf, 1981). Independent comparisons using the $\chi^{2}$ analysis with the Yates correction (Sokal and Rohlf, 1981) showed no difference between PBS and DM-1-injected cases $\left(\chi^{2}\right.$ $=0.632 ; p=n s)$, but a significant difference was found between no antibody and DM-2 $\left(\chi^{2}=5.47 ; p<0.025\right)$.

The disruption in nonradial cell migration did not affect radial cell migration. Greater than $90 \%$ of clones, despite the presence or absence of nonradial cell dispersion, showed radial dispersion from the ventricular zone independent of whether the embryo was exposed to DM-1, DM-2, or no antibody. Occasional clones $(\sim 8 \%)$ showed cells restricted to the ventricular zone indicating no radial migration had occurred. Given that clones restricted to the ventricular zone were found in approximately equal proportions in treated and untreated embryos, radial cell migration appears unaffected. Embryos injected with DM-1 showed similar numbers of both radially and nonradially distributed clones when compared to control embryos. In contrast, nonradial cell dispersion was not observed in the dorsal diencephalon in any embryo injected with DM-2.

Nonradial cell migration was specifically blocked in the diencephalon of chick embryos. Examination of the mesencephalon (tectum), where nonradial cell dispersion has also been observed in chick embryos (Gray and Sanes, 1991; Ryder and Cepko, 1994), shows that nonradial cell migration was not affected by the injection of DM-2 or DM-1 (Fig. 5). DM-GRASP is not expressed in the regions of the tectum or telencephalon where this nonradial cell migration occurs. These data indicate that the block in nonradial cell migration is specific for the diencephalon where DM-GRASP is expressed on the migrating cells.

Because the injection of DM-2 inhibited nonradial cell migration, the morphological consequences of blocking this pathway of migration were examined in E10 and E14 embryos. After injection of antibody on E4, E5, and E6, embryonic brains were fixed, sectioned, and stained with hemotoxylin and eosin. Embryos injected with DM-1 showed no morphological abnormalities (Fig. 6) when compared to control embryos. In contrast, embryos injected with DM-2 showed a disruption in the normal anatomy and size of the diencephalon (Fig. 6). Despite the severe cytoarchitectural abnormalities, the disruption appeared specific. For example, the ventral lateral geniculate nucleus appeared to be preserved in embryos injected with DM-2, whereas the nucleus rotundum and other dorsal nuclei were absent or markedly distorted. The dorsal diencephalon was specifically affected, whereas the tectum and cerebellum appeared normal. Occasional brains showed anomalies of the telencephalon, however, we have focused on the diencephalon where we could correlate the morphological studies with our studies of lineage and clonal dispersion (Golden and Cepko, 1996; Golden et al., 1997).

The diencephalon was found to be both small and the morphology was disrupted. The small size of the diencephalon raised the possibility that the injection of DM-2 antibodies specifically interrupted cell proliferation and/or led to increased cell death. To determine if cell death was increased by injection of the DM-2 antibody, TUNEL assays were performed to assess the amount of cell death after injection of no-antibody, DM-1, or DM-2. No qualitative difference was observed between embryos injected with PBS, DM-1, or DM-2 (Fig. 7). A higher percentage of cells were labeled with the TUNEL technique on E8, when compared to E7, however, this was in embryos from all experimental groups, indicating a normal increase in cell death in the diencephalon during development (Fig. 7). The number of TUNEL-positive cells was again low on E10 (Fig. 7).

To determine if cell proliferation was inhibited by the antibody injections, BrdU incorporation studies were performed. Immunofluorescent staining for BrdU again showed no qualitative difference in the number of labeled cells after injection of no antibody, DM-1, or DM-2 (data not shown). A review of the E10 and E14 hematoxylin- and eosin-stained sections indicates a greater density of cell nuclei in the diencephalon. These data suggest that the DM-2 antibody may have pleotropic affects that include blocking nonradial cell migration and other developmental processes that result in the abnormal morphology of the diencephalon. 

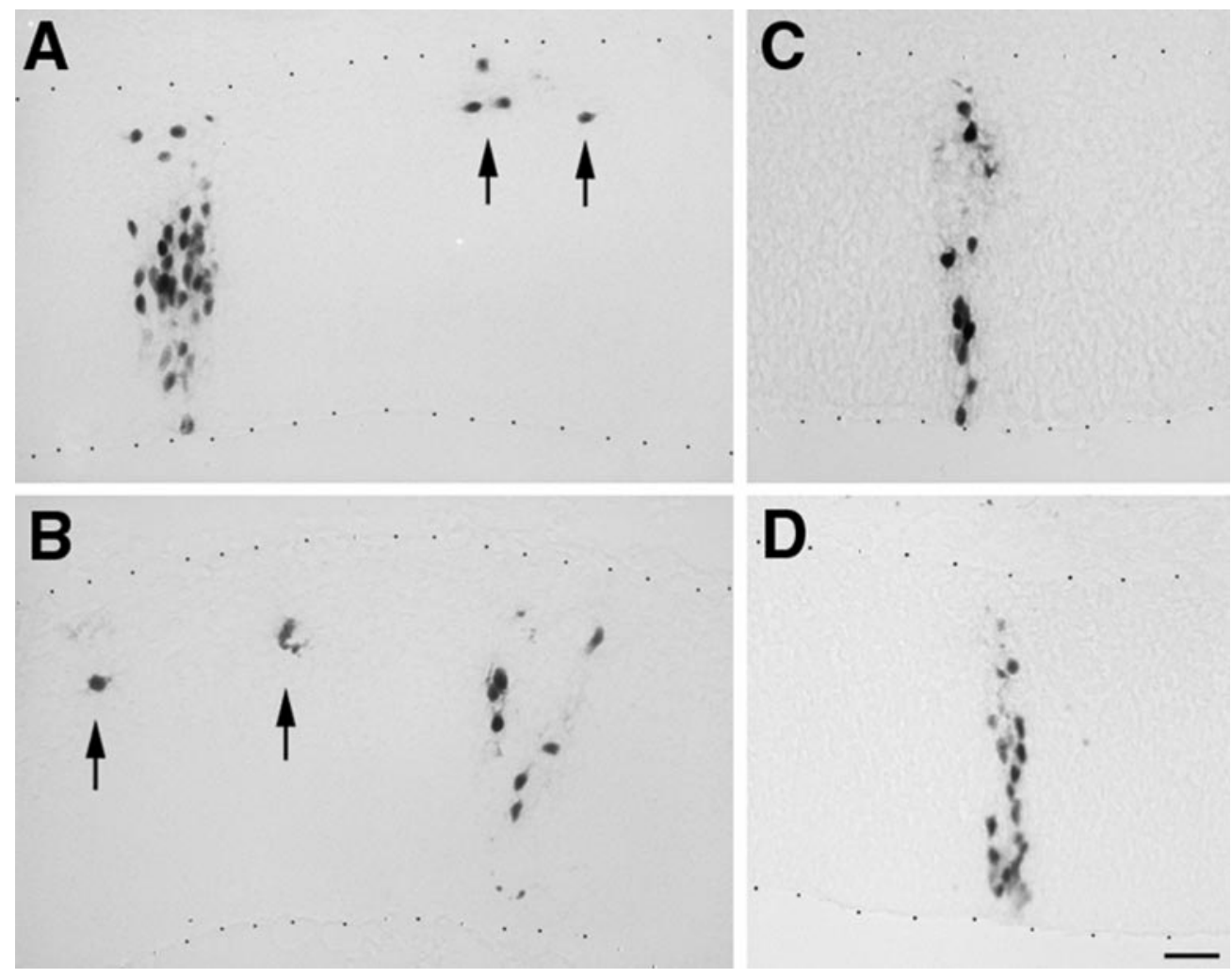

Figure 4. Embryos injected with DM-1 or no antibody $(A, B)$ showed clones (identified with the LZ12 retrovirus) with both radial and nonradial cell dispersion. The ventricle is at the bottom (defined by the bottom series of black dots), and the pial surface is at the top (defined by the top series of black dots) in each image. Radial clones span from the VZ at the bottom of each image toward the top. Nonradial cell dispersion (arrows) was identified in approximately one-third of all clones $(A, B)$. Only radial clones were found in embryos treated with DM-2 $(C, D$; with two exceptions, see Results).

Table 1. Number (and percentage) of clones showing radial (Radial) migration alone or radial and nonradial (Nonradial) cell dispersion after embryos were injected with control media (No Antibody), DM-1, or DM-2

\begin{tabular}{|c|c|c|c|c|c|}
\hline \multicolumn{2}{|c|}{ No Antibody $(n=16)$} & \multicolumn{2}{|c|}{ DM-1 $(n=16)$} & \multicolumn{2}{|c|}{ DM-2 $(n=25)$} \\
\hline Radial & Nonradial & Radial & Nonradial & Radial & Nonradial \\
\hline 16 & $5(31 \%)$ & 18 & $5(28 \%)$ & 28 & 2 \\
\hline 26 & $16(38 \%)^{*}$ & & & & \\
\hline
\end{tabular}

*Data from Golden et al. (1997).

$n$ is the number of chick embryos examined for each experimental condition.

\section{DISCUSSION}

Two patterns of cell migration are recognized during early development of the CNS, radial and nonradial. These two patterns of cell migration have been observed at all levels of the neural axis, suggesting they are both essential components of development (Baehr et al., 1988; Bourrat and Sotelo, 1988; Ono and Kawamura, 1989; Austin and Cepko, 1990; Leber et al., 1990; Gray and Sanes, 1991; Halliday and Cepko, 1992; Martinez et al., 1992; Walsh and Cepko, 1992; Fishell et al., 1993; Ryder and Cepko, 1994; Marin and Puelles, 1995; O’Rourke et al., 1995, 1997; Golden and Cepko, 1996; O'Rourke, 1996; Phelps et al., 1996; Szele and Cepko, 1996, 1998; Anderson et al., 1997; Golden et al., 1997; Tan et al., 1998). Numerous molecules have been shown to participate in the radial pathway of cell migration, whereas the molecular mechanisms of nonradial cell migration are only beginning to be elucidated. Our data indicate that DMGRASP is necessary for nonradial cell migration in the chick diencephalon, thus providing an opportunity to begin constructing a molecular pathway for this pattern of cell migration.

DM-GR ASP is a type I transmembrane protein and a member of the Ig superfamily (Burns et al., 1991). Although the precise cellular and biochemical function of DM-GRASP remains unknown, it is likely to mediate cell-cell interactions. Cell-cell and cell-extracellular matrix molecule interactions are required for other patterns of cell migration in the CNS (Stitt and Hatten, 1990; Fishell and Hatten, 1991; Asou et al., 1992; Grumet, 1992; Husmann et al., 1992; Fishman and Hatten, 1993; Komuro and Rakic, 1993; Mittal and David, 1994; Ono et al., 1994; Thomaidou et al., 1995; Anton et al., 1996, 1997; Komuro and Rakic, 1996; Zheng et al., 1996; Rio et al., 1997). One mechanism through which DM-GRASP can function is by way of homophilic interactions. Biochemical studies indicate homophilic interactions between DM-GRASP expressed on adjacent axons facilitate axon outgrowth (Burns et al., 1991). We observed DM-GRASP expression on putative nonradially migrating cells and on axons, the later were previously observed by others in the chick forebrain (Chédotal et al., 1995). Together these data might suggest homophilic interactions may also guide nonradial cell migration. They also imply nonradial cell migration is axon dependent as previously hypothesized (Golden et al., 1997).

Other molecules have also been shown to bind to DM-GR ASP (Bowen et al., 1995; DeBernardo and Chang, 1996). One example 


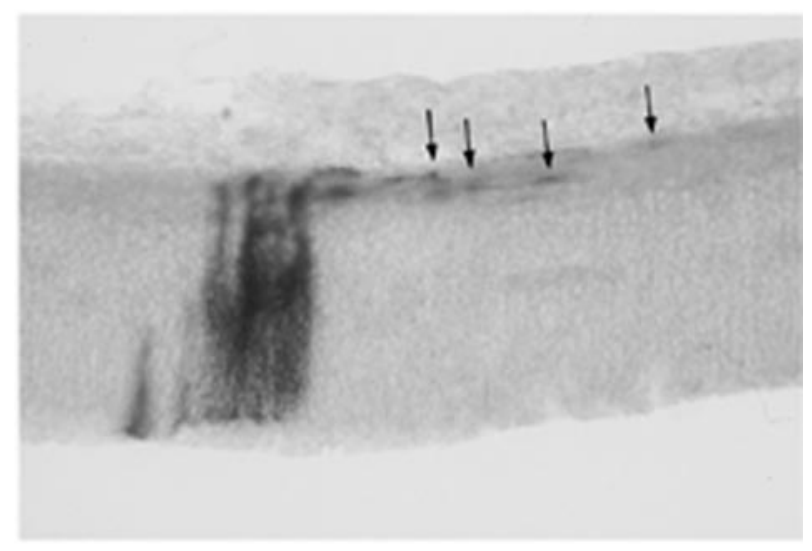

Figure 5. Nonradial dispersion of cells (arrows) is observed in the tectum of DM-2-treated embryos where DM-GRASP is not expressed at this developmental time (clones identified by alkaline phosphatase histochemistry after CHAPOL retroviral infection).

is Ng-CAM (DeBernardo and Chang, 1996). Ng-CAM is of particular interest because it is located on the surface of axons in the chick (Lemmon and McLoon, 1986) and is required for cell migration in the adult songbird (Barami et al., 1994; Goldman et al., 1996). Ng-CAM is also expressed on the surface of axons in the diencephalon at the time nonradial cell migration is initiated (Golden et al., 1997). This provides a second or alternative substrate for DM-GRASP to interact with during cell migration. We are currently testing the role of $\mathrm{Ng}$-CAM in nonradial cell migration (B. Uher and J. Golden, unpublished data).

Our data suggest that cell migration along nonradial pathways is required for normal morphological development of the dien-

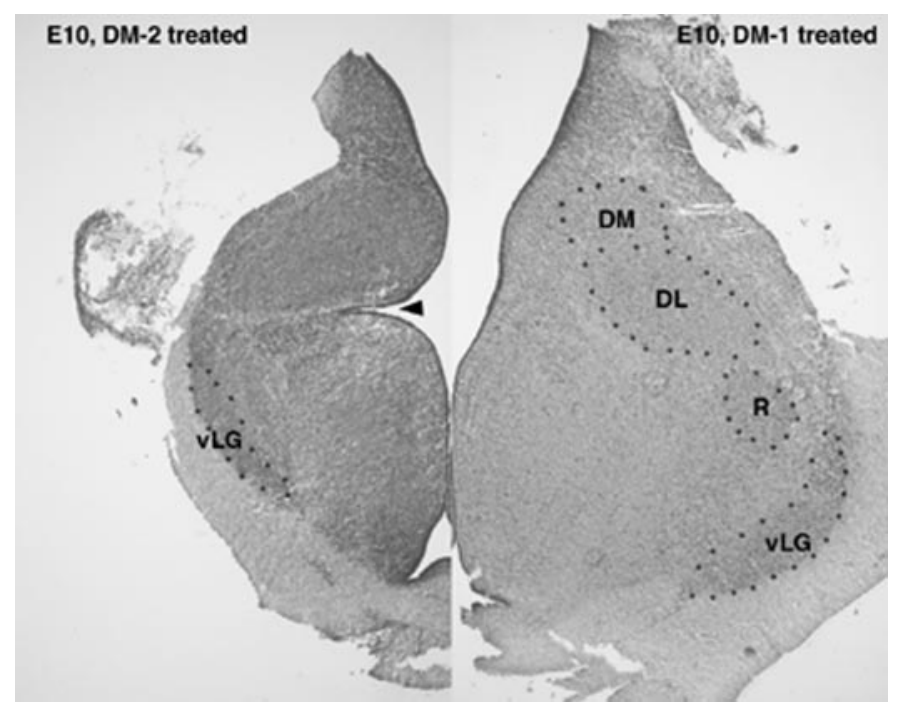

Figure 6. Histological sections of the diencephalon of E10 embryos treated with DM-1 (right) or DM-2 (left). Both sections are taken at approximately the same anatomic level. Embryos injected with DM-1 showed normal diencephalic morphology, whereas those injected with DM-2 had a small diencephalon, loss of neuropil, and poorly organized nuclear groups. This is particularly true for the dorsal nuclei. The ventral nuclei (e.g., ventral lateral geniculate body; $v L G$ ) were somewhat better preserved although small, whereas the dorsal nuclei (e.g., nucleus rotundum, $R$; dorsal lateral, $D L$; and dorsal medial, $D M$ ) nuclei could not be delineated. Furthermore, the sulcus limitans (arrowhead) was extremely deep in DM-2-treated embryos compared to controls or embryos treated with DM-1.
DM-1

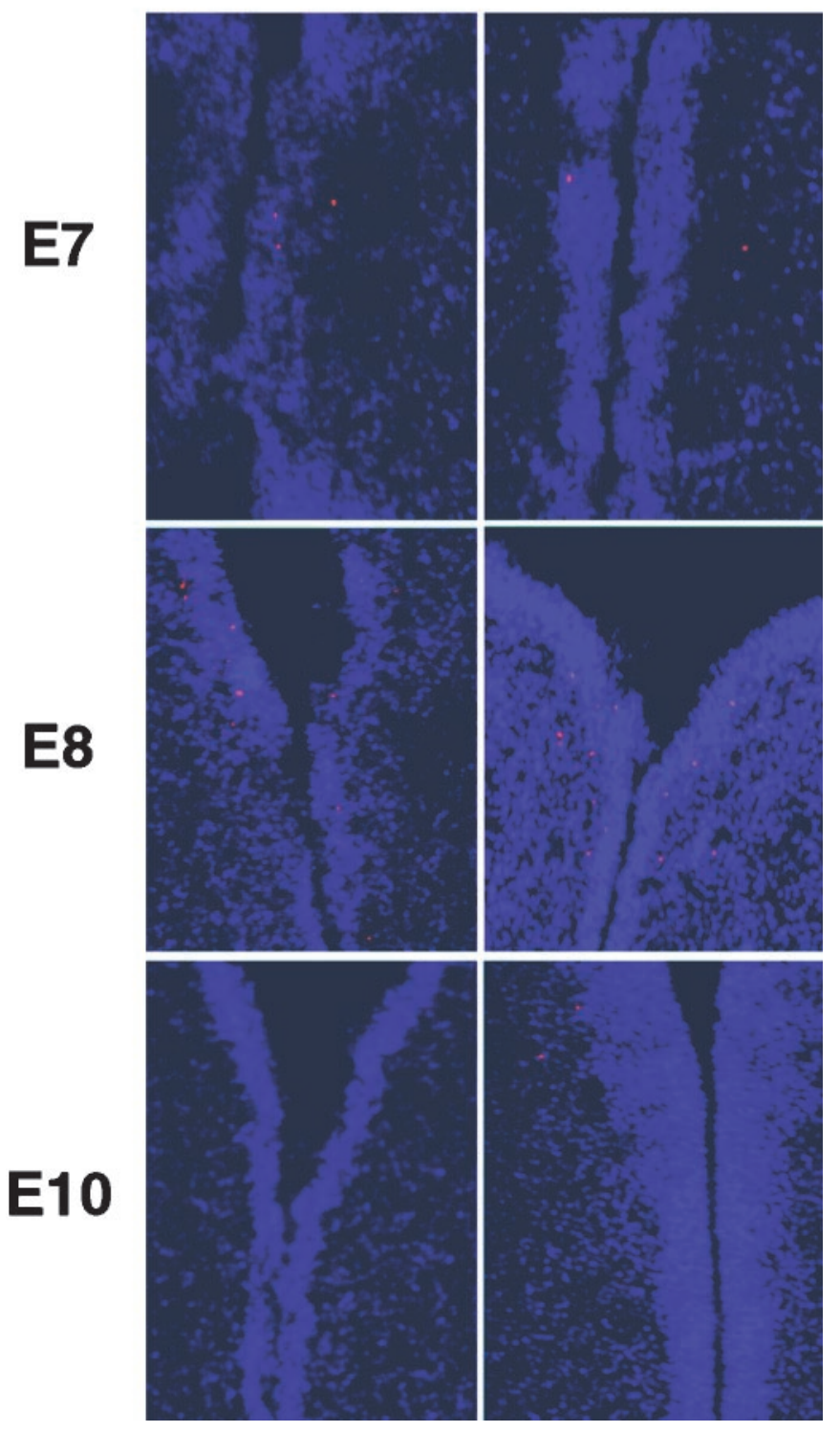

Figure 7. TUNEL assay on sections through the diencephalon of E7, E8, and E10 embryos after injection of either DM-1 or DM-2. No difference was observed in the pattern or number of TUNEL + cells between these two experimental groups or those injected with PBS alone. A slight increase in the number of TUNEL-positive cells was observed at E8 in all of the experimental groups. These data likely reflect the normal programmed cell death that occurs in the diencephalon during development.

cephalon. Given the marked differences in size between the DM-1- and DM-2-treated embryos, we first addressed whether the morphological disruption resulted from increased cell death or a decrease in cell proliferation. Our data indicate that a marked increase in cell death did not result from injection of the DM-2 supernatant. A qualitative difference in cell proliferation was also not observed; however, we did not test whether our treatment altered the length of the cell cycle. An increased density of cells was noted in the diencephalon of embryos exposed to DM-2 (D. Heffron and J. Golden, unpublished observations). These data suggest that the disruption of the diencephalon is primarily a result of blocking nonradial cell migration, however, 
DM-2 may have additional effects on diencephalic development that are also reflected in the morphological phenotype.

The disruption of nonradial cell migration resulted in abnormal nuclear organization. The diencephalon, like the midbrain and hindbrain, is organized into discrete collections of neurons known as nuclei. Each nucleus has a specific function, set of functions, or defined neurochemical transmitter. Our data indicate that nonradial cell migration is required in at least the diencephalon for the organization of these functional neuronal groups. The dorsal diencephalon was particularly affected while some nuclei of the ventral diencephalon could be defined. Given that DM-GRASP is expressed preferentially in the dorsal diencephalon, the data on nuclear disorganization appears to correlate with this expression. Furthermore, the two clones that showed nonradial cell migration were located ventrally where nuclear organization was better preserved and DM-GRASP is not expressed.

Our data imply other molecules are likely to participate in the guidance of nonradial cell migration in other regions of the CNS. As noted above, nonradial cell migration has been identified at virtually every level of the developing nervous system. We have observed nonradial cell migration in the tectum and in two clones in the ventral diencephalon in embryos injected with the DMGRASP blocking antibody. Given that DM-GRASP is not expressed in these areas at the time of development we have studied, it was not surprising for nonradial migration to appear normal in these regions of the neural tube. However, this does imply that distinct molecules will control nonradial cell migration in various regions of the neural tube.

The role of nonradial cell migration during CNS development has been an open subject. In the mouse telencephalon at least some cortical GABAergic interneurons are derived from the ganglionic eminence and must migrate tangentially into the cortex (Anderson et al., 1997). A population of layer one neurons also migrates tangentially from the germinal zone of the olfactory tubercle (Meyer et al., 1998). Finally, in the spinal cord, interneurons migrate on commissural neurons (Phelps and Vaughn, 1995; Phelps et al., 1996). These data provide some insight into specific cell types that use nonradial cell migration. We are currently determining the phenotypes of the cells that migrate nonradially. The cytology of cells within widely dispersed clones suggests these cells will be many phenotypes (Golden et al., 1997).

The rostral migratory stream is a specialized route of cell migration (Lois et al., 1996). This pathway is present in adulthood, although the timing of its developmental onset remains unclear. This pathway of cell migration uses a specialized glial structure for directing "chains" of neurons into the olfactory bulb (Lois et al., 1996). These neurons also become interneurons in the olfactory bulb (Luskin, 1998). Like nonradial cell migration during CNS development, little is known about the molecules involved in guiding this pathway of cell migration.

Our data provide insight into both the role of nonradial cell migration in the chick diencephalon and a first step toward elucidating the molecular and cellular guidance mechanisms for this pathway of cell movement. The role and mechanisms of nonradial cell migration in other regions of the nervous system remains to be determined. Identifying the molecules involved in guiding nonradial cell migration will allow additional studies that will begin to answer some of these provocative questions. Additional genetic studies, disrupting these genes in mice or zebrafish, are also likely to provide valuable information into the role of nonradial cell migration during development. Finally, the identification of DM-GRASP as a necessary molecule for nonradial cell migration will allow us to begin identifying other components of this cellular pathway. Knowing that DM-GRASP can interact with Ng-CAM (DeBernardo and Chang, 1996) has already prompted us to study the later cell adhesion molecule and Axonin, which is another known binding partner for Ng-CAM (Kuhn et al., 1991).

\section{REFERENCES}

Anderson SA, Eisenstat DD, Shi L, Rubenstein JL (1997) Interneuron migration from basal forebrain to neocortex: dependence on Dlx genes. Science 278:474-476.

Anton E, Cameron R, Rakic P (1996) Role of neuron-glial junctional domain proteins in the maintenance and termination of neuronal migration across the embryonic cerebral wall. J Neurosci 16:2283-2293.

Anton ES, Marchionni MA, Lee KF, Rakic P (1997) Role of GGF/ neuregulin signaling in interactions between migrating neurons and radial glia in the developing cerebral cortex. Development 124:3501-3510.

Asou H, Miura M, Kobayashi M, Uyemura K, Itoh K (1992) Cell adhesion molecule L1 guides cell migration in primary reaggregation cultures of mouse cerebellar cells. Neurosci Lett 144:221-224.

Austin CP, Cepko CL (1990) Cellular migration patterns in the developing mouse cerebral cortex. Development 110:713-732.

Baehr W, Falk JD, Bugra K, Triantafyllos JT, McGinnis JF (1988) Isolation and analysis of the mouse opsin gene. FEBS Lett 238:253-256.

Barami K, Kirschenbaum B, Lemmon V, Goldman SA (1994) $\mathrm{N}$-cadherin and $\mathrm{Ng}$-CAM/8D9 are involved serially in the migration of newly generated neurons into the adult songbird brain. Neuron 13:567-582.

Bourrat F, Sotelo C (1988) Migratory pathways and neuritic differentiation of inferior olivary neurons in the rat embryo. Axonal tracing study using the in vitro slab technique. Brain Res 467:19-37.

Bowen MA, Patel DD, Li X, Modrell B, Malacko AR, Wang WC, Marquardt H, Neubauer M, Pesando JM, Francke U, Haynes BF, Aruffo A (1995) Cloning, mapping, and characterization of activated leukocyte-cell adhesion molecule (ALCAM), a CD6 ligand. J Exp Med 181:2213-2220.

Burns FR, von Kannen S, Guy L, Raper JA, Kamholz J, Chang S (1991) DM-GRASP, a novel immunoglobulin superfamily axonal surface protein that supports neurite extension. Neuron 7:209-220.

Chédotal A, Pourquié O, Sotelo C (1995) Initial tract formation in the brain of the chick embryo: selective expression of the BEN/SC1/DMGRASP cell adhesion molecule. Eur J Neurosci 7:198-212.

DeBernardo AP, Chang S (1996) Heterophilic interactions of DMGRASP: GRASP-NgCAM interactions involved in neurite extension. J Cell Biol 133:657-666.

Ericson J, Morton S, Kawakami A, Roelink H, Jessell TM (1996) Two critical periods of Sonic Hedgehog signaling required for the specification of motor neuron identity. Cell 87:661-673.

Fishell G, Hatten M (1991) Astrotactin provides a receptor system for CNS neuronal migration. Development 113:755-765.

Fishell G, Mason C, Hatten M (1993) Dispersion of neural progenitors within the germinal zones of the forebrain. Nature 362:636-638.

Fishman R, Hatten M (1993) Multiple receptor systems promote CNS neural migration. J Neurosci 13:3485-3495.

Fournier-Thibault C, Pourquie O, Rouaud T, Le Douarin NM (1999) BEN/SC1/DM-GRASP expression during neuromuscular development: a cell adhesion molecule regulated by innervation. J Neurosci 19:1382-1392.

Galileo D, Gray G, Owens G, Majors J, Sanes J (1990) Neurons and glia arise from a common progenitor in chicken optic tectum: demonstration with two retroviruses and cell type-specific antibodies. Proc Natl Acad Sci USA 87:458-462.

Geisert EE, Frankfurter A (1989) The neuronal response to injury as visualized by immunostaining of class III beta-tubulin in the rat. Neurosci Lett 102:137-141.

Golden JA, Cepko CL (1996) Clones in the chick diencephalon contain multiple cell types and siblings are widely dispersed. Development 122:65-78.

Golden J, Fields-Berry S, Cepko C (1995) Construction and character- 
ization of a highly complex retroviral library for lineage analysis. Proc Natl Acad Sci USA 92:5704-5708.

Golden J, Zitz J, McFadden K, Cepko C (1997) Cell migration in the developing chick diencephalon. Development 124:3525-3533.

Golden JA, Bracilovic A, McFadden KA, Beesley JS, Rubenstein JLR, Grinspan JB (1999) Ectopic bone morphogenetic proteins 5 and 4 in the chicken forebrain leads to cyclopia and holoprosencephaly. Proc Natl Acad Sci USA 96:2439-2444.

Goldman SA, Williams S, Barami K, Lemmon V, Nedergaard M (1996) Transient coupling of $\mathrm{Ng}$-CAM expression to $\mathrm{NgCAM}$-dependent calcium signaling during migration of new neurons in the adult songbird brain. Mol Cell Neurosci 7:29-45.

Gray G, Sanes J (1991) Migratory paths and phenotypic choices of clonally related cells in the avian optic tectum. Neuron 6:211-225.

Grumet M (1992) Structure, expression, and function of Ng-CAM, a member of the immunoglobulin superfamily involved in neuron-neuron and neuron glia adhesion. J Neurosci Res 31:1-13.

Halliday AL, Cepko CL (1992) Generation and migration of cells in the developing striatum. Neuron 9:15-26.

Hamburger V, Hamilton H (1951) A series of normal stages in the development of the chick embryo. J Morphol 88:49-91.

Hatten ME (1999) Central nervous system neuronal migration. Annu Rev Neurosci 22:511-539.

Husmann K, Faissner A, Schachner M (1992) Tenascin promotes cerebellar granule cell migration and neurite outgrowth by different domains in the fibronectin type III repeats. J Cell Biol 116:1475-1486.

Komuro H, Rakic P (1993) Modulation of neuronal migration by NMDA receptors. Science 260:95-97.

Komuro H, Rakic P (1996) Intracellular Ca2+ fluctuations modulate the rate of neuronal migration. Neuron 17:275-285.

Kuhn TB, Stoeckli ET, Condrau MA, Rathjen FG, Sonderegger P (1991) Neurite outgrowth on immobilized axonin-1 is mediated by a heterophilic interaction with L1(G4). J Cell Biol 115:1113-1126.

Leber S, Breedlove S, Sanes J (1990) Lineage, arrangement, and death of clonally related motoneurons in the chick spinal cord. J Neurosci 10:2451-2462.

Lemmon V, McLoon S (1986) The appearance of an L1-like molecule in the chick primary visual pathway. J Neurosci 6:2987-2994.

Lois C, Garcia-Verdugo JM, Alvarez-Buylla (1996) Chain migration of neuronal precursors. Science 271:978-981.

Luskin MB (1998) Neuroblasts of the postnatal mammalian forebrain: their phenotype and fate. J Neurobiol 36:221-233.

Marin F, Puelles L (1995) Morphological fate of rhombomeres in quail/ chick chimeras: a segmental analysis of hindbrain nuclei. Eur J Neurosci 7:1714-1738.

Martinez S, Puelles L, Alvarado-Mallart RM (1992) Tangential neuronal migration in the avian tectum: cell type identification and mapping of regional differences with quail/chick homotopic transplants. Brain Res Dev Brain Res 66:153-163.

Meyer G, Soria JM, Martinez-Galan JR, Martin-Clemente B, Fairen A (1998) Different origins and developmental histories of transient neurons in the marginal zone of the fetal and neonatal rat cortex. J Comp Neurol 397:493-518.

Mittal B, David S (1994) The role of an astrocyte surface molecule in neuronal migration in the developing rat cerebellum. Mol Cell Neurosci 5:78-86.

O'Rourke N (1996) Neuronal chain gangs: homotypic contacts support migration into the olfactory bulb. Neuron 16:1061-1064.
O'Rourke N, Sullivan D, Kaznowski C, Jacobs A, McConnell S (1995) Tangential migration of neurons in the developing cerebral cortex. Development 121:2165-2176.

O'Rourke NA, Chenn A, McConnell SK (1997) Postmitotic neurons migrate tangentially in the cortical ventricular zone. Development 124:997-1005.

Ono K, Kawamura K (1989) Migration of immature neurons along tangentially oriented fibers in the subpial part of the fetal mouse medulla oblongata. Exp Brain Res 78:290-300.

Ono K, Toasiewicz H, Magnuson T, Rutishauser U (1994) N-CAM mutation inhibits tangential neuronal migration and is phenocopied by enzymatic removal of polysialic acid. Neuron 13:595-609.

Phelps PE, Vaughn JE (1995) Commissural fibers may guide cholinergic neuronal migration in developing rat cervical spinal cord. J Comp Neurol 355:38-50.

Phelps P, Barber R, Vaughn J (1996) Nonradial migration of interneurons can be experimentally altered in spinal cord slice cultures. Development 122:2013-2022.

Pourquie O, Coltey M, Thomas JL, Le Douarin NM (1990) A widely distributed antigen developmentally regulated in the nervous system. Development 109:743-752.

Pourquie O, Corbel C, Le Caer JP, Rossier J, Le Douarin NM (1992) BEN, a surface glycoprotein of the immunoglobulin superfamily, is expressed in a variety of developing systems. Proc Natl Acad Sci USA 89:5261-5265.

Rakic P (1990) Principles of neural cell migration. Experientia 46:882-891.

Rio C, Rieff HI, Qi P, Khurana TS, Corfas G (1997) Neuregulin and erbB receptors play a critical role in neuronal migration. Neuron 19:39-50.

Ryder EF, Cepko CL (1994) Migration patterns of clonally related granule cells and their progenitors in the developing chick cerebellum. Neuron 12:1011-28.

Stitt T, Hatten M (1990) Antibodies that recognize astrotactin block granule neuron binding to astroglia. Neuron 5:639-649.

Szele F, Cepko C (1996) A subset of clones in the chick telencephalon arranged in rostrocaudal arrays. Curr Biol 6:1685-1690.

Szele FG, Cepko CL (1998) The dispersion of clonally related cells in the developing chick telencephalon. Dev Biol 195:100-113.

Tan SS, Kalloniatis M, Sturm K, Tam PP, Reese BE, Faulkner-Jones B (1998) Separate progenitors for radial and tangential cell dispersion during development of the cerebral neocortex. Neuron 21:295-304.

Tanaka H, Obata K (1984) Developmental changes in unique cell surface antigens of chick embryo spinal motorneurons and ganglion cells. Dev Biol 106:26-37.

Thomaidou D, Dori I, Patsavoudi E (1995) Developmental expression and functional characterization of the 4C5 antigen in the postnatal cerebellar cortex. J Neurochem 64:1937-1944.

Walsh C, Cepko CL (1992) Widespread dispersion of neuronal clones across functional regions of the cerebral cortex. Science 255:434-440.

Zhang G, Slaughter C, Humphries EH (1995) v-rel Induces ectopic expression of an adhesion molecule, DM-GR ASP, during B-lymphoma development. Mol Cell Biol 15:1806-1816.

Zheng C, Heintz N, Hatten M (1996) CNS gene encoding astrotactin, which supports neuronal migration along glial fibers. Science 272:417419 . 